\title{
Nuancing the role of social skills- a longitudinal study of early maternal psychological distress and adolescent depressive symptoms
}

\author{
Wendy Nilsen ${ }^{1,2^{*}}$, Evalill Bølstad Karevold ${ }^{3}$, Jannike Kaasbø $\|^{4}$ and Anne Kjeldsen ${ }^{5,6}$
}

\begin{abstract}
Background: Social skills might play an important role for the relationship between maternal psychological distress and subsequent development of depressive symptoms. The majority perspective is that social skills is adaptive and protective, but there is a need to also highlight the potential maladaptive effect of social skills in some settings or for some sub groups.

The current study examined the longitudinal interplay between maternal-reported psychological distress in early childhood (age 1.5), and offspring reports on social skills and depressive symptoms in early (age 12.5) and middle adolescence (age 14.5).
\end{abstract}

Methods: We used data from the Tracking Opportunities and Problems Study (TOPP), a community-based longitudinal study following Norwegian families to examine direct links and interactions between early maternal distress (measured with the Hopkins Symptom Checklist) and early adolescent offspring social skills (measured with the Social Skills Rating System) and middle adolescent depressive symptoms (measured with the Moods and Feelings Questionnaire) in 370 families (in total 740 mothers and adolescents).

Results: Exposure to childhood maternal distress predicted offspring depressive symptoms in middle adolescence. Higher social skills in early adolescence predicted lower levels of depressive symptoms for girls, but not for boys, in middle adolescence. An interaction effect was found in which adolescents exposed to early maternal distress who reported high social skills in early adolescence had the highest level of depressive symptoms in middle adolescence.

Conclusions: The findings highlight the nuances in the role of social skills for adolescent depressive symptoms - having the potential to be both adaptive as well as maladaptive for some subgroups (those experiencing maternal psychological distress). This has important implications for social skill programs.

Keywords: Social skills, Adolescence, Depression, Maternal depression, Longitudinal studies

\footnotetext{
* Correspondence: wendy.nilsen@fhi.no

${ }^{1}$ Work Research Institute, OsloMet - Oslo Metropolitan University, Postbox 4,

St. Olavs plass, 0130 Oslo, Norway

2Department of Mental Disorders, Norwegian Institute of Public Health,

Postbox 4404, Nydalen, 0403 Oslo, Norway

Full list of author information is available at the end of the article
}

\section{Ciomed Central}

(c) The Author(s). 2018 Open Access This article is distributed under the terms of the Creative Commons Attribution 4.0 International License (http://creativecommons.org/licenses/by/4.0/), which permits unrestricted use, distribution, and reproduction in any medium, provided you give appropriate credit to the original author(s) and the source, provide a link to the Creative Commons license, and indicate if changes were made. The Creative Commons Public Domain Dedication waiver (http://creativecommons.org/publicdomain/zero/1.0/) applies to the data made available in this article, unless otherwise stated. 


\section{Background}

Adolescence is a well-documented period for the development of depressive symptoms [1-3]. Adolescent subthreshold levels of symptoms are associated with diagnosed depression and other adverse outcomes in adulthood [4, 5]. Studying factors and mechanisms that contributes to early identification of depressive symptoms before they become chronic is therefore essential for effective intervention and prevention. One single factor alone (e.g., gender, maternal distress, temperament) is seldom responsible for the development of internalizing problems. In line with the biopsychosocial model of development and developmental psychopathology, an integrative perspective including both contextual and individual factors is likely to extend our understanding of the complex etiology of depressive symptomatology. Maternal psychological distress (i.e., symptoms of anxiety and depression) is one the most well-known early famil$\mathrm{ial} /$ contextual risk factors for depressive development in adolescents [6-8], and social skills are shown to be a protective individual factor in adolescence [9-13]. However, the impact of the interplay between early maternal distress and social skills on the development of depressive symptoms in adolescence is less examined. Thus, in the current paper, we aim to study the interplay between early childhood maternal psychological distress (age 1.5) and early adolescent social skills (age 12.5) to predict depressive symptoms in middle adolescence (age 14.5).

\section{Maternal psychological distress and adolescent depressive symptoms}

There is an increased risk of psychological distress in offspring when parents experience psychological distress [6-8], even for mild levels of depressive symptoms [1416]. The transitional mechanisms are suggested to work through both biological (genetic or in utero transitions) $[17,18]$ and environmental influences (i.e., less sensitive, and emotional unavailable parenting) $[8,19]$, or through a combination of these [20]. The framework of developmental psychopathology highlights the possibility that similar types of stressors, such as maternal depression, may have different effects at different developmental stages $[21,22]$. Theories of early life vulnerability for instance, emphasize the possibility of sensitive stages where stressors may have a particular strong impact early in life as compared to other stages [23]. In line with this, early exposure to maternal psychological distress is suggested to interfere with the development of important processes and competencies in childhood, such as attachment, emotion regulation, interpersonal skills, and stress responses, which can give a heightened risk for subsequent development of depression [24]. Albeit several studies support the long-term adverse impact of early sensitive period of experiencing maternal depressive symptomatology $[8,25]$, there is less research examining the potential impact social skills might have on the association between maternal psychological distress and the development of subsequent adolescent depressive symptomatology. A recent review emphasized the need for studies identifying processes accounting for positive outcomes such as social skills for children and adolescents with depressed mothers [26].

\section{Maternal psychological distress, social skills and adolescent depressive symptoms}

Good social skills is defined as being able to interact with other people in a way that is both appropriate (e.g., not eliciting negative responses from others) and effective (e.g., achieving one's goal with the interaction) [13]. The social skills construct contains different dimensions, like perspective taking (cognitive), empathy (emotional), and cooperation and self-control (behavioral) [27]. Despite social competence being defined as a broader term that includes social skills as well as other behavioral, cognitive, and emotional traits necessary to develop and maintain adequate social relationships, the terms social skills and social competence are often used interchangeably [28]. Thus, in the current paper we will refer to studies focusing on both social competence and skills. Good social skills can make it easier to manage stressors and challenges connected to developmental transitions such as adolescence, and thus protect the development of subsequent adverse outcomes. Supporting this, crosssectional and longitudinal findings report good social skills to be associated with less depressive symptoms in adolescence [9-13].

Based on the social skills deficit theory $[29,30]$, the social skills deficit vulnerability model argues that low social skills create vulnerability for developing psychosocial problems when experiencing stress $[13,31]$. While some studies examining exposure to stressful events support this hypothesis [13, 31, 32], few have examined exposure to maternal depression or psychological distress as example of experiencing stress. Still, studies examining terms such as social functioning (i.e. functioning in social life, close friendship, romantic and family relationship), which is related to social skills, have examined the interplay between maternal depression and depression in their offspring [33-35]. A recent study reported that high social functioning was an important protective factor for adolescent offspring of depressed parents, with a twofold increase of having good mental health for those displaying high social functioning [35]. Also, another study reported an interaction effect in which depressive symptoms was higher for adolescent offspring of depressed mothers with low interpersonal functioning in a cross-sectional study [33]. This was supported in a longitudinal five-year follow-up study of the same sample 
[33, 34]. With the strength of conducting clinical interviews of both mothers and children, these studies indicate a complex interplay between interpersonal factors, maternal depression and adolescent depression. The current study aimed to expand upon these studies to examine social skills capturing abilities such as empathy, cooperation, assertiveness and self-control in adolescents.

While the social skills deficit theory offers a valuable insight in the protective trait of social skills or the negative effect of social skills deficits, a more nuanced theoretical perspective advocates a view of social skills as both adaptive and maladaptive. Despite its initial counterintuitiveness, researchers have suggested that social skills can be used in maladaptive manners, in that individuals might take into consideration others so much that it overrule their own needs [36]. Additionally, having higher social skills can be used as a means to manipulate others behavior, which have been indicated by findings linking bullying behavior and high social skills in some groups of adolescents [37]. Researchers have indicated that being emphatic, a prosocial trait, as a response to parental depressive symptoms might be both adaptive and maladaptive [38]. Findings from a recent study support this notion [39]. This finding showed that high empathy was associated with higher internalizing problems in children with depressed mothers, but not in children with non-depressed mothers, indicating that social skills are not always protective. It was hypothesized that high level of empathy can lead to emotional overarousal when experiencing others' pain or discomfort. A nuanced perspective of social skills is thus important, because of the changeable nature of these skills, which is a main element of many prevention/ intervention programs [40, 41]. In a worst-case scenario, social skills training programs that do not inhabit this nuancing perspective might increase vulnerability to contextual stressors for some subgroups of children and adolescents. No published studies have, to our knowledge, examined whether social skills during early adolescence are adaptive or maladaptive in the context of exposure to childhood maternal psychological distress with comprehensive longitudinal multi-informant design.

\section{Gender differences}

It is important to gain more knowledge on genderspecific pathways to the development of depressive symptomatology in adolescence, due to the consistently reported finding that girls report higher depression levels from puberty and onwards [2, 3, 42]. Girls are two to three times more likely to report depressive symptoms in both population-based and clinical samples than boys are [2, 3, 42-44]. Gender-specific vulnerability to maternal psychological distress seems more inconsistent
[45]. Findings indicate an interaction between gender and developmental stage in which boys seems more vulnerable for maternal distress in infancy (e.g., [46]), while girls seem to more vulnerable during adolescence [45, 47]. However, there are also studies showing no gender differences $[48,49]$.

It is suggested that girls, compared to boys, are especially reactive to interpersonal stressors due to increased impact of hormones and gender socialization $[42,50]$. Findings supporting this is however contradictory with some studies reporting girls to be more interpersonally vulnerable compared to boys (i.e., stronger associations between social skills and depressive symptoms) [50], while other studies are inconclusive with no gender differences [12]. Similarly, adolescent girls report higher social skills in some studies [51], and lower social skills in other studies compared to boys [52-54]. In the few studies examining the interplay between maternal depressive symptomatology and offspring social skills and depressive symptoms, some gender-specific findings have emerged. A study reported that social skills mediated the association between maternal depression and adulthood depression in female, but not male offspring [55], indicating a specific interpersonal stressor-related pathway to depressive symptoms for adult female offspring having experienced maternal depression.

\section{The current study}

In accordance with former findings [33-35], we predict that: 1) Higher levels of maternal psychological distress at age 1.5 predict higher depressive symptoms at age 14 . 5, and 2) Higher social skills at age 12.5 predict lower depressive symptoms at age 14.5. Due to few former findings and in light of the nuancing view of social skills, we examine the following exploratory research questions: 3) Do social skills at age 12.5 positively or negatively affect the relation between maternal psychological distress at age 1.5 and depressive symptoms at age 14.5 (i.e., interaction effects)? and 4) Are there gender differences in the interplay between early maternal psychological distress, social skills and depressive symptoms?

\section{Methods}

\section{Participants and procedure}

Families from 19 geographic health care areas in eastern Norway were invited to complete a survey questionnaire when attending the 18-month vaccination visit for the index child in 1993 (Time 1 (T1)) [56, 57]. Regional Committees for Medical and Health Research Ethics (REC) approved the data collection. The 19 health care areas differed considerably and were overall representative of the diversity of social environments in Norway ${ }^{34}$. Routinely, more than $95 \%$ of all Norwegian families with children attend a public health program during the first 
4 years of the child's life. Of the 1081 invited families, 929 families (86\%) participated at T1. Families participating at $\mathrm{T} 1$ received a similar questionnaire when the children were ages 2.5 (T2), 4.5 (T3), 8.5 (T4), 12.5 (T5), 14.5 (T6), 16.5 (T7) and 19 (T8). Mothers completed questionnaires at all waves, fathers were included from $\mathrm{T} 6$, and the children/adolescents themselves completed questionnaires from $\mathrm{T} 5$.

Since the main interests were examining maternal distress in early childhood, and early adolescent social skills and depression, we used reports at ages 1.5, 12.5 and 14 . 5 for the current study. Of the 913 mothers who participated at T1, 481 (52\% of the T1 sample) also participated at T6, 566 children $(61 \%$ of the T1 sample of mothers) participated at T5 and $458(50 \%)$ at T6 with an even gender distribution (51\% girls).

The current sample included 370 mothers-child dyads $(n=740)$ with mothers reports on $\mathrm{T} 1$ and $\mathrm{T} 6$, and adolescents' report on T5 and T6. Adolescents responded to social skills for the first time at age 12.5 (T5). Eight individuals were excluded from the analyses, due to more than half of the information missing on one of the main variables of interests, leaving the sample to be 362 mothers-child dyads, with 159 mothers-son dyads $(n=308)$, and 203 motherdaughter dyads $(n=406)$.

Baseline background information showed that nonparticipating mothers did not significantly differ from participating mothers in maternal age, education, employment status, number of children and marital status [56]. Attrition analyses indicated that of several variables (e.g., maternal education, maternal work participation, family financial stress, marital status, stressful life events and depressive symptoms), only low maternal educational level predicted dropout for mothers $[58,59]$ and adolescents [60,61]. Male gender predicted dropout for adolescents [60, 61]. Associations between mental health and the other examined variables at baseline (e.g., maternal education, maternal work participation) did not differ among dropout versus remaining families, suggesting that estimated associations between variables are generalizable [58].

\section{Measures}

Maternal psychological distress was assessed with the 25-item version of the Hopkins Symptoms Check List (HSCL-25) [62-64], which has shown good psychometric qualities both internationally and in Norwegian samples for the measurement of symptoms of depression and anxiety [62-65]. The responses are rated on a fourpoint scale ranging from 1 "Not at all" to 4 "Extremely" affected. The items "thought of ending my life" and "loss of sexual interest or pleasure" were excluded from the questionnaire in $\mathrm{T} 1$ and $\mathrm{T} 6$ because they were perceived as offensive in a pilot study. A total mean score was calculated based on these 23 items, with a Cronbach alpha (internal reliability) of .90 at both waves in the current study.

Adolescent depressive symptoms were assessed with the Short Mood and Feelings Questionnaire (SMFQ) $[66,67]$. The SMFQ consists of 13 questions drawn from original 34-item Moods and Feelings Questionnaire, with the response categories "Seldom true", "Sometimes true" and "Often true". One item, "I had difficulties concentrating" was not included in the questionnaire because of content overlap. One item ('I feel lonely') was similar to some constructs from the SSRS scale (see below). Analyses excluding this item did not change the results, so the item was included in all analysis. The SMFQ has shown satisfactory psychometric qualities in both international $[66,67]$ and Norwegian samples $[68,69]$. A total mean score was used, with a Cronbach alpha (internal reliability) of .88 in the current study.

Social skills were assessed with a shortened form of the Social Skills Rating System (SSRS) at T5 [70]. The SSRS has shown satisfactory psychometric qualities in both international [70, 71] and Norwegian samples [72-74]. Reliability and factor analyses of the original 39 item scale at former time points in the TOPP-study (T4) assessed with parental reports, led to the development of a 24-item version used for subsequent waves (unpublished findings). Former publications imply that the 24-item version has predictive validity [75]. The Cronbach alpha (internal reliability) for the shortened form of SSRS was high (.88) for the current sample. SSRS measures four social skills dimensions: Cooperation (six items), Assertiveness (six items), Empathy (six items) and Self-control (six items). The response categories were originally three ("Never", "Sometimes", and "Very Often"), but two extra response categories ("Seldom", and "Often") was added in the Norwegian version after former recommendations [72]. An index was constructed by computing the mean score for the total scale.

Possible confounder variables included maternal psychological distress at T6 and socio-economic indicators (SES) at T1 composed of maternal education, maternal work participation, and family financial stress.

\section{Analytic strategy}

Statistical analysis was performed using SPSS (Statistical Package for the Social Sciences). T-tests were conducted to examine gender differences in adolescent depressive symptoms, social skills and maternal psychological distress. Hierarchical block regression analysis was used to examine direct effects and interaction effects on selfreported adolescent depressive symptoms at T6 on adolescent girls and boys separately Table 1 . 
Table 1 Characteristics of participating families at baseline (T1)

\begin{tabular}{|c|c|}
\hline Variables & \\
\hline Maternal age (years), mean (SD) & $30(4.7)$ \\
\hline \multicolumn{2}{|l|}{ Maternal education \% } \\
\hline Basic schooling ( $\leq 9$ years) & $9.5 \%$ \\
\hline Basic schooling+ (10-11 years) & $27.6 \%$ \\
\hline Finished high school (13 years) & $25.4 \%$ \\
\hline Higher education ( $\geq 14$ years) & $37.6 \%$ \\
\hline \multicolumn{2}{|l|}{ Maternal work status \% } \\
\hline No paid work & $37.0 \%$ \\
\hline Part-time paid work & $32.0 \%$ \\
\hline Full-time paid work & $31.0 \%$ \\
\hline \multicolumn{2}{|l|}{ Maternal relationship status \% } \\
\hline Married/cohabiter & $91.2 \%$ \\
\hline Single & $8.8 \%$ \\
\hline \multicolumn{2}{|l|}{ Maternal mother tongue $\%$} \\
\hline Norwegian & $93.6 \%$ \\
\hline Other than Norwegian & $6.4 \%$ \\
\hline \multicolumn{2}{|l|}{ Family economy \% } \\
\hline We manage well/very well & $53.4 \%$ \\
\hline We manage & $40.7 \%$ \\
\hline We manage poorly/very poorly & $5.9 \%$ \\
\hline \multicolumn{2}{|l|}{ Pariety \% } \\
\hline One child & $48.2 \%$ \\
\hline Two children & $37.2 \%$ \\
\hline Three to ten children & $14.6 \%$ \\
\hline \multicolumn{2}{|l|}{ Offspring infant gender \% } \\
\hline Girl & $51.1 \%$ \\
\hline Boy & $48.9 \%$ \\
\hline
\end{tabular}

The mean score of adolescent depressive symptoms was log transformed to compensate for skewed data. In the first step, maternal distress at T1 and self-reported adolescent social skills at T5 were inserted to examine direct effects. Following, a variable constructed by the product between the standardized value of maternal distress at T1 and the standardized value of self-reported adolescent social skills at T5 was inserted representing the interaction effect. In the final step, we adjusted for $\mathrm{SES}$ at $\mathrm{T} 1$ and concurrent maternal psychological distress at $\mathrm{T} 6$.

\section{Results}

See 1 for descriptive characteristics of the sample at baseline. The age of the mothers ranged from age 19 to $46(\mathrm{M}=30 ; \mathrm{SD}=4.7)$, and a minority of the mothers (9\%) were single. Eight percent of the mothers had 9 years schooling or less, while $18 \%$ had a college or university education of 4 years or more. Roughly, equal numbers of mothers worked fulltime (32\%), part-time (31\%), or had no paid work (37\%).

Table 2 presents the descriptive information of all variables and t-tests of gender differences. Adolescent girls scored significantly higher than boys did on depressive symptoms and social skills with medium effect sizes. There were no gender differences in experiences of early maternal psychological distress. Tables 3 and 4 show correlations for adolescent girls and boys, respectively. While the associations between early and concurrent maternal distress and adolescent depression were significant for both girls and boys, associations between early adolescent social skills and adolescent depressive symptoms were only significant for adolescent girls. Early maternal distress did not correlate with adolescent social skills for either girls or boys.

Tables 5 and 6 present findings from hierarchical block regression analysis for boys and girls separately. In step 1 , early maternal distress significantly predicted adolescent depressive symptoms for both girls and boys. While social skills in step 2 were a significant negative predictor and increased the explained variance of adolescent girls' depressive symptoms, it was not a significant predictor for boys.

The interaction term of early maternal distress and early adolescent social skills added in step 3 was a significant positive predictor and increased the explained variance significantly for adolescent boys' depressive symptoms, but not for girls (see $F_{\text {change }}$ scores in Tables 5 and 6).

When adjusting for concurrent maternal distress and socio-economic indicators, the majority of the effects in step 3 remained for both girls and boys. Only the effect of early maternal distress on adolescent girls' depressive symptoms became nonsignificant $(p=.052)$. Before conducting adjustments, the final model explained more variance in adolescent girls' (12\%) compared to boys' depressive symptoms (6\%).

Post hoc graphical figures were conducted to explore the direction of the interaction. To do so, we dichotomized the measure of maternal distress according to former recommendations of a cut-off score of mean $=1$. 75 [76, 77], and conducted median-split of social skills (due to lack of cut-off recommendations the short form version of 24 items). See Fig. 1 for a graphical depiction of the interaction effects. Confidence intervals show that for those experiencing no or low maternal psychological distress in childhood, high social skills is associated with lesser depressive symptoms, than low social skills. This was found or girls only. For those experiencing early maternal distress, this pattern was vice versa. For both boys and girls experiencing early maternal distress and reporting high social skills in adolescence the level of depressive symptoms was significantly higher (as indicated by 
Table 2 Descriptive information and t-tests of gender differences in the main variables

\begin{tabular}{|c|c|c|c|c|c|c|c|c|c|}
\hline \multirow[t]{2}{*}{ Variables } & \multicolumn{2}{|c|}{ Males $\left(n=162-166^{+}\right)$} & \multicolumn{2}{|c|}{ Females $\left(n=203-204^{+}\right)$} & \multicolumn{2}{|c|}{ Total $\left(n=365-370^{+}\right)$} & \multirow[b]{2}{*}{ t } & & \multirow[b]{2}{*}{$d$} \\
\hline & Mean & (SD) & $\overline{M e a n}$ & (SD) & $\overline{M e a n}$ & $(S D)$ & & & \\
\hline Early maternal distress (age 1.5) & 1.30 & $(.28)$ & 1.32 & $(.31)$ & 1.31 & $(.29)$ & -.56 & & .07 \\
\hline Social skills (age 12.5) & 4.04 & $(.45)$ & 4.19 & $(.42)$ & 4.12 & $(.44)$ & -3.21 & $* *$ & .34 \\
\hline Depressive symptoms (age 14.5) & .23 & (.28) & .43 & $(.40)$ & .34 & (.36) & -5.64 & $* * *$ & .58 \\
\hline
\end{tabular}

${ }^{*} p<.05,{ }^{* *} p<.01,{ }^{* * *} p<.001$

${ }^{+}$Samples sizes vary due to missing information at some waves

no overlapping confidence intervals) than all other groups. The three other groups had overlapping confidence intervals showing no significance difference between these groups. The wider confidence intervals for the high maternal distress groups are due to smaller sample sizes in both the groups of girls and boys having experienced high maternal distress.

\section{Discussion}

The current study examined the interplay between early childhood maternal psychological distress and early adolescence social skills and adolescent depressive symptoms within the perspective of early life vulnerability theories. In line with our predictions, we found a prospective 12-year longitudinal link between early maternal distress and depressive symptoms in middle adolescence (age 14.5), supporting former studies showing that early childhood is a sensitive period for the exposure to maternal distress $[6-8,59]$. This pathway was present for both girls and boys, and persisted when adjusting for confounding variables for boys, but became borderline significant for girls. Despite not being a surprising finding, the link between early childhood maternal distress and adolescent depressive symptoms is a prerequisite for our later predictions.

Our second prediction of a direct pathway from early adolescence social skills (age 12.5) to middle adolescence depressive symptoms (age 14.5), with low levels of social skills predicting higher depressive symptoms, was also supported. However, this pathway was only evident for girls, supporting theories and findings of girls being more interpersonally vulnerable compared to boys $[42,50,78]$. There might be other interpersonal factors not captured by the SSRS that might be relevant for boys, as suggested by a former study using the same data material as the current study [59]. In this former study, boys' development of internalizing symptoms were significantly more affected by high levels of shyness and low activity levels compared to girls [59]. The current finding underscores the gender-specific direct pathway further from total social skills to depression development for girls.

Third, we found that for children who were exposed to maternal distress in early childhood, higher social skills in early adolescence increased the level of depressive symptoms in middle adolescence. These findings are in contrast to former theories and findings of social skills generally having a stress-buffering protective effect $[6,13,31,32,79,80]$, but support recent indications of social skills being maladaptive in certain settings [36, 38, 39]. This is also in contrast to former findings reporting high social functioning behavior to be protective [33-35]. When measuring maternal distress and social skills as continuous variables, this was only found for boys. However, when examining dichotomous variables (i.e., high versus low distress and social skills) this interaction was found for both girls and boys. In line with theories suggesting social skills to be protective, we also found that for adolescent girls exposed to no or low maternal distress in early childhood, higher social skills were protective against depressive symptoms.

Our findings highlight the importance of having a nuanced picture of social skills. While the social skills deficit theory offer a valuable insight in the adverse effects of social skills deficits, there is need for a more nuanced perspective also incorporating the possibility of high social skills to be maladaptive in some settings. Despite the counter-intuitiveness of the notion that social skills might be maladaptive for certain sub groups (i.e.,

Table 3 Pearson's correlations between the main variables in adolescent girls ( $n=203)$

\begin{tabular}{|c|c|c|c|c|c|c|c|c|c|}
\hline Variables & 1 & 2 & & 3 & & 4 & & 5 & \\
\hline 1. Adolescent depression (age 14.5) & - & .19 & ** & -.30 & $* *$ & .16 & ** & -.10 & \\
\hline 2. Maternal distress (age 1.5) & & - & & -.05 & & .36 & ** & -.32 & ** \\
\hline 3. Social skills (age 12.5) & & & & - & & -.15 & * & .08 & \\
\hline 4. Maternal distress (age 14.5) & & & & & & - & & -.20 & ** \\
\hline 5. Sosioeconomic indicators & & & & & & & & - & \\
\hline
\end{tabular}

${ }^{*} p<.05 ;{ }^{* *} p<.01$ 
Table 4 Pearson's correlations between the main variables in adolescent boys $(n=159)$

\begin{tabular}{|c|c|c|c|c|c|c|c|c|}
\hline Variables & 1 & 2 & & 3 & 4 & & 5 & \\
\hline 1. Adolescent depression (age 14.5) & - & .16 & * & .00 & .16 & ** & .00 & ** \\
\hline 2. Maternal distress (age 1.5) & & - & & -.10 & .34 & ** & -.25 & ** \\
\hline 3. Social skills (age 12.5) & & & & - & .04 & & -.06 & \\
\hline 4. Maternal distress (age 14.5) & & & & & - & & -.09 & \\
\hline 5. Sosioeconomic indicators & & & & & & & - & \\
\hline
\end{tabular}

children experiencing early childhood stress such as maternal distress), they are in line with both former suggestions that social skills can make individuals to be too considerate towards others, forgetting their own needs, or can be used as a means to manipulate others [36-38]. Moreover, a recent study reported that being emphatic as a response to parental depressive symptoms might be maladaptive [39]. The reason for few other empirical findings of the potential maladaptive effect of social skills, might be due to difficulties in publishing finding that counter the established understanding of social skills as adaptive. It is essential to replicate these findings in other samples using a hypothesis-testing approach for the validation and generalization of the findings to other samples. For instance, we did not examine the potential effect of early paternal psychological distress, as the fathers of the adolescents did not participate in the first five waves. Considering the increasing number of fathers participating in their children's life today, and emerging findings on the link between paternal and offspring psychopathology $[81,82]$, future studies are encouraged to also include fathers. Moreover, future studies should also aim to examine the mechanisms underlying this phenomenon, such as emotional over arousal when experiencing other's pain or discomfort.

Despite being outside the focus of the current study, the correlation analyses revealed an interesting lack of association between early maternal distress and subsequent adolescent social skills for both girls and boys. This is in contrast to some former findings (e.g., 45 , 55). Potential reasons for this is examining a community-based sample (as opposed to a clinical sample) or the longer follow-up period as compared to former studies. Moreover, it might be that the current sample lacks the most severe cases of maternal psychological distress that might affect long-term social skills [See also limitation section for thorough discussion on dropout rates and generalizations].

\section{Strengths and limitations}

The current study benefited from a 13-year longitudinal prospective community sample of 362 mother-child dyads ( $n=724$ individuals), with separate informants for maternal psychological distress (i.e., mothers' selfreports) and adolescent social skills and depressive symptoms (i.e., adolescents' self-reports), as well as wellvalidated psychometric instruments. There are still several limitations. First, the use of self-report and not observational data increases the risk for shared method variance to inflate the strength of associations. However, the use of multiple waves and two informants (i.e., mothers' reports on their psychological distress, and adolescent's reports on their social skills and depressive symptoms) reduces this common method bias. Moreover, using adolescent's own reports instead of maternal reports also reduces potential depression-distortion bias (i.e., that mothers who score high on depressive

Table 5 Maternal distress and adolescent social skills as predictors of depressive symptoms in adolescent girls $(n=203)$

\begin{tabular}{|c|c|c|c|c|c|c|c|c|c|c|c|c|}
\hline \multirow[t]{2}{*}{ Predictors } & \multicolumn{2}{|c|}{ Model 1} & & \multicolumn{2}{|c|}{ Model 2} & & \multicolumn{2}{|c|}{ Model 3} & & \multicolumn{3}{|c|}{ Model 4} \\
\hline & $\bar{B}$ & $t$ & & $\bar{B}$ & $t$ & & $\bar{B}$ & $t$ & & $\bar{B}$ & $t$ & \\
\hline Early maternal distress (age 1.5) & .21 & 3.10 & ** & .23 & 3.41 & $* * *$ & .19 & 2.60 & $* *$ & .16 & 1.96 & \\
\hline Adolescent social skills (age 12.5) & & & & -.29 & -4.37 & $* * *$ & -.28 & -4.09 & $* * *$ & -.27 & -3.87 & $* * *$ \\
\hline Maternal distress $\times$ social skills & & & & & & & .08 & 1.01 & & .08 & 1.02 & \\
\hline Current maternal distress(age 14.5) & & & & & & & & & & .06 & .81 & \\
\hline Socioeconomic indicators & & & & & & & & & & -.02 & -.31 & \\
\hline$R$ & & .045 & & & .129 & & & .133 & & & .137 & \\
\hline$R_{\text {adj }}^{2}$ & & .041 & & & .120 & & & .120 & & & .115 & \\
\hline$F_{\text {change }}$ & & 9.58 & $* *$ & & 19.07 & $* * *$ & & 1.02 & & & .40 & \\
\hline
\end{tabular}

${ }^{*} p<.05 ;{ }^{* *} p<.01 ;{ }^{* * *} p<.001$ 
Table 6 Maternal distress and adolescent social skills as predictors of depressive symptoms in adolescent boys $(n=159)$

\begin{tabular}{|c|c|c|c|c|c|c|c|c|c|c|c|}
\hline \multirow[t]{2}{*}{ Predictors } & \multicolumn{2}{|c|}{ Model 1} & & \multicolumn{2}{|c|}{ Model 2} & & \multicolumn{2}{|c|}{ Model 3} & & \multicolumn{2}{|c|}{ Model 4} \\
\hline & $B$ & $t$ & & $B$ & $t$ & & $B$ & $t$ & & $\bar{B}$ & $t$ \\
\hline Early maternal distress (age 1.5) & .21 & 2.67 & $* *$ & .21 & 2.68 & $* *$ & .25 & 3.13 & ** & .21 & 2.43 \\
\hline Adolescent social skills (age 12.5) & & & & .02 & .30 & & .01 & .17 & & .00 & .01 \\
\hline Maternal distress $\times$ social skills & & & & & & & .19 & 2.40 & $* *$ & .19 & 2.37 \\
\hline Current maternal distress (age 14.5) & & & & & & & & & & .09 & 1.01 \\
\hline Socioeconomic indicators & & & & & & & & & & .00 & .03 \\
\hline$R$ & & .044 & & & .044 & & & .078 & & & .084 \\
\hline$R_{\text {Adj }}^{2}$ & & .037 & & & .032 & & & .060 & & & .054 \\
\hline$F_{\text {change }}$ & & 7.15 & $* *$ & & .07 & & & 5.77 & * & & .51 \\
\hline
\end{tabular}

${ }^{*} p<.05 ;{ }^{* *} p<.01 ;{ }^{* * *} p<.001$

symptoms might report their children's symptoms more negatively).

Second, we did not examine reciprocal effects between depressive symptoms and social skills across childhood in children and their mothers because the children were only invited to participate in the study with self-reports from adolescence and onwards. Parallel symptom development in family member might however affect each other, as reported in other studies and should be pursued in future studies [83].

Third, the instrument used to measure social skills, SSRS has been updated after our study was conducted, to "the Social Skills Improvement System-Rating Scales" (SSIS-RS) [84]. The changes have led to inclusion of more subscales (e.g., "communication"), and studies in both Norway and North America shows that the new instrument had significantly higher reliability scores on some of the overlapping subscales $[74,84]$. However, the old instrument (SSRS) was found to correlate highly with the new instrument (SSIS-RS) [74]. Future studies should consider using the new instrument.

Also, respecting pilot study participants' wishes we deleted two items from the Hopkins Symptom Check List (i.e., "thought of ending my life" and "loss of sexual interest or pleasure") - thus leaving out some variation.

Finally, as expected in a longitudinal prospective study - the dropout rate in the current sample proposes caution in generalizing the findings to the other populations. Attrition rates as high as $40-60 \%$ is not uncommon in longitudinal studies and only systematic non-random drop-outs represent a problem [84]. The only systematic difference between drop-outs and remaining participants was low level of education and male gender [58-61]. However, a range of other indicators such as work participation, family financial stress, marital status, stressful life events and depressive

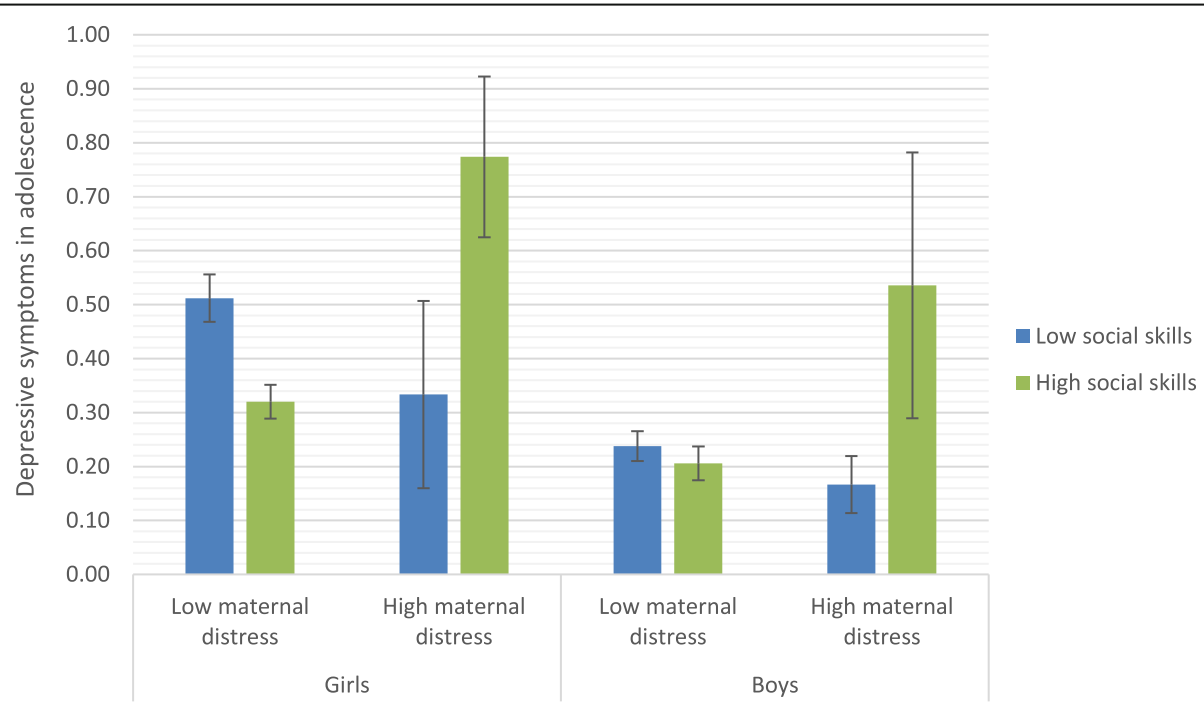

Fig. 1 Mean levels of self-reported symptoms of depression in adolescent boys and girls (age 14.5) (with confidence intervals based on standard errors) for high versus low maternal distress and social skills 
symptoms did not affect dropping-out, and associations between variables at baseline did not differ among dropout versus remaining families later in the TOPP-study [58], suggesting that estimated associations between variables are generalizable. Thus, we believe that our sample is representative of similar samples of "normal", but not to the same extent representative of high risk populations. Note however that the Norway is characterized by less inequality due to a redistribution of resources by the welfare state [85]. This suggests that despite dropout being predicted by low educational status, the sample might still be generalizable to the majority of Norwegian families. As such, the findings might be more easily generalized to other Northern European societies that are similar to Norway with regards to the social welfare system as opposed to societies that are very different. Still, due to the risk of associations being underestimated in samples including parents with higher education, we suggest that future studies to be persistent in their recruitment of families from all layers of society.

\section{Conclusions}

The current study examined the longitudinal interplay between early maternal distress (age 1.5) and adolescent offspring social skills (age 12.5) and depressive symptoms (age 14.5) in 362 mothers-adolescents dyads. The findings highlight the importance of examining the complex interplay between both individual (e.g., social skills) and familial/contextual variables (e.g., maternal distress) in their prediction of adolescent internalizing problems. The findings replicate the established link between childhood maternal distress and adolescent depressive symptoms, but also shed light on the role of social skills for this link. The results of the current study indicate that high social skills in early adolescence can be adaptive, in its direct link to subsequent low depressive symptoms 2 years later. The most noteworthy findings is however that high social skills for some individuals (i.e., those with mothers reporting high psychological distress) is maladaptive (i.e., linked to higher depressive symptoms in adolescence). It is thus important that social skills training efforts are able to tailor their programs to both those needing help to increase their use of social skills trait, but also to those needing help to put their own needs in front of others in some settings. More research is needed to further examine these nuances in social skills.

\footnotetext{
Acknowledgements

This research is based on data from the Tracking Opportunities and Problems (TOPP) belonging to the Norwegian Institute of Public Health. We acknowledge all the participating families and their voluntary effort over several years, as well as the health care personnel who contributed with the data collection the first three waves. We acknowledge the founder of the TOPP-study, Dr. Kristin S. Mathiesen (Norwegian Institute of Public Health), all researchers who contributed with the data collection throughout the years,
}

and The Research Council of Norway, which have been the main contributor for funding the data collections.

\section{Funding}

WN was funded by the Research Council of Norway's Program for Sickness Absence, Work and Health (grant project number 218373) and AK by the the Research Council of Norway's Program for Alcohol and Drug Research (grant project number 213759) while writing the current paper. The funding bodies did not participate in any part of the process of the current paper - the design of the study, data collection, analyses, data interpretation or writing of the manuscript.

\section{Availability of data and materials}

Restrictions apply to the availability of these data, which were used under license for the current study, and so are not publicly available. The data can be found at secure servers at the Norwegian Institute of Public Health, and are protected under confidentiality laws and cannot be shared or passed on to anyone who is not authorized by The Regional Committees for Medical and Health Research Ethics in Norway (REC) and the Norwegian Institute of Public Health for access to the data.

\section{Authors' contributions}

WN, AK and EBK participated in making the questionnaires and collecting the data at several waves. WN prepared the data, planned and conducted the analyses. WN, AK, EBK and JK contributed in the conceptualization of the research questions for the paper and the interpretation of the data. WN drafted the manuscript. AK and JK participated considerably in creating the text. WN, AK, EBK and JK all read and revised the manuscript critically for intellectual content. All authors gave final approval of the version to be published, take responsibility for the content and agree to be accountable for all aspects of the work in ensuring that questions related to the accuracy or integrity of any part of the work are appropriately investigated and resolved.

\section{Ethics approval and consent to participate}

The study has been approved by The Norwegian Data Protection Authority and REC - the Regional Committees for Medical and Health Research Ethics in Norway (REC). Study participation was voluntary. The TOPP study started in 1992/1993 when written consent in research studies was not a requirement. However, in later years, REC has reviewed all information given to participants and concluded that the study fulfils essential requirements for informed consent. The information spans oral and written information the parents and their children have been given both before and after the data collections about topics and results for current and future research, the confidentiality of the participants, the possibility to skip questions, and the right to withdraw from the study at any point. The children were invited through their mothers, who were given questionnaire surveys and separate response envelopes for themselves and their children.

Consent for publication

Not applicable.

\section{Competing interests}

The authors declare that they have no competing interests.

\section{Publisher's Note}

Springer Nature remains neutral with regard to jurisdictional claims in published maps and institutional affiliations.

\section{Author details}

${ }^{1}$ Work Research Institute, OsloMet - Oslo Metropolitan University, Postbox 4, St. Olavs plass, 0130 Oslo, Norway. ${ }^{2}$ Department of Mental Disorders, Norwegian Institute of Public Health, Postbox 4404, Nydalen, 0403 Oslo, Norway. ${ }^{3}$ Department of Psychology, University of Oslo, Oslo, Norway. ${ }^{4}$ Department of Health Research, SINTEF Technology and Society, Klæbuveien 153, Trondheim 7049, Norway. ${ }^{5}$ Department of Child Development, Norwegian Institute of Public Health, Postbox 4404, Nydalen, Oslo 0403, Norway. ${ }^{6}$ Bjørknes University College, Lovisenberggata 13, 0456 Oslo, Norway. 


\section{Received: 12 April 2017 Accepted: 26 March 2018} Published online: 10 April 2018

\section{References}

1. Costello EJ, Copeland W, Angold A. Trends in psychopathology across the adolescent years: what changes when children become adolescents, and when adolescents become adults? J Child Psychol Psychiatry. 2011;52(10): 1015-25. https://doi.org/10.1111/j.1469-7610.2011.02446.x.

2. Rudolph KD. Adolescent depression. In: IHGCL H, editor. Handbook of depression. New York: The Guilford Press; 2009.

3. Wichstrom $L$. The emergence of gender difference in depressed mood during adolescence: the role of intensified gender socialization. Dev Psychol. 1999;35(1):232-45. https://doi.org/10.1037/0012-1649.35.1.232.

4. Pine DS, Cohen E, Cohen P, Brook J. Adolescent depressive symptoms as predictors of adult depression: Moodiness or mood disorder? Am J Psychiat. 1999;156:1:133-35. https://doi.org/10.1176/ajp.156.1.133.

5. Shankman SA, Lewinsohn PM, Klein DN, Small JW, Seeley JR, Altman SE. Subthreshold conditions as precursors for full syndrome disorders: a 15-year longitudinal study of multiple diagnostic classes. J Child Psychol Psyc. 2009; 50(12):1485-94. https://doi.org/10.1111/j.1469-7610.2009.02117.x.

6. Goodman SH. Depression in mothers. Annu Rev Clin Psycho. 2007;3:107-35. https://doi.org/10.1146/annurev.clinpsy.3.022806.091401.

7. Goodman SH, Rouse MH, Connell AM, Broth MR, Hall CM, Heyward D. Maternal depression and child psychopathology: a meta-analytic review. Clin Child Fam Psych. 2011;14(1):1-27. https://doi.org/10.1007/s10567-0100080-1.

8. Leckman-Westin E, Cohen PR, Stueve A. Maternal depression and motherchild interaction patterns: association with toddler problems and continuity of effects to late childhood. J Child Psychol Psyc. 2009;50(9):1176-84. https://doi.org/10.1111/j.1469-7610.2009.02083.x.

9. Letcher P, Smart D, Sanson A, Toumbourou JW. Psychosocial Precursors and Correlates of Differing Internalizing Trajectories from 3 to 15 Years. Soc Dev. 2009;18(3):618-46. https://doi.org/10.1111/j.1467-9507.2008.00500.x.

10. Burt KB, Obradovic J, Long JD, Masten AS. The interplay of social competence and psychopathology over 20 years: testing transactional and cascade models. Child Dev. 2008;79(2):359-74. https://doi.org/10.1111/j. 1467-8624.2007.01130.x.

11. HermanStahl M, Petersen AC. The protective role of coping and social resources for depressive symptoms among young adolescents. J Youth Adolescence. 1996;25(6):733-53. https://doi.org/10.1007/Bf01537451.

12. Ohannessian CM, Lerner RM, Lerner JV, von Eye A. Does self-competence predict gender differences in adolescent depression and anxiety? J Adolescence. 1999;22(3):397-411. https://doi.org/10.1006/jado1999.0231.

13. Segrin C. Social skills deficits associated with depression. Clin Psychol Rev 2000;20(3):379-403. https://doi.org/10.1016/S0272-7358(98)00104-4

14. Mars B, Collishaw S, Hammerton G, Rice F, Harold GT, Smith D, Jones RB, Sellers R, Potter R, Craddock N, et al. Longitudinal symptom course in adults with recurrent depression: impact on impairment and risk of psychopathology in offspring. J Affect Disorders. 2015;182(4):32-8. https:// doi.org/10.1016/jjad201504.018.

15. Connell AM, Goodman SH. The association between psychopathology in fathers versus mothers and children's internalizing and externalizing behavior problems: a meta-analysis. Psychol Bull. 2002;128(5):746-73. https://doi.org/10.1037//0033-2909.128.5.746.

16. West AE, Newman DL. Worried and blue: mild parental anxiety and depression in relation to the development of young children's temperament and behavior problems. Parent-Sci Pract. 2003;3(2):133-54 https://doi.org/10.1207/S15327922par0302_02.

17. Elgar FJ, McGrath PJ, Waschbusch DA, Stewart SH, Curtis LJ. Mutual influences on maternal depression and child adjustment problems. Clin Psychol Rev. 2004;24(4):441-59. https://doi.org/10.1016/j.cpr.2004.02.002.

18. Sullivan PF, Neale MC, Kendler KS. Genetic epidemiology of major depression: review and meta-analysis. Am J Psychiatry. 2000;157(10):155262. https://doi.org/10.1176/appi.ajp.157.10.1552.

19. Lovejoy MC, Graczyk PA, O'Hare E, Neuman G. Maternal depression and parenting behavior: a meta-analytic review Clin Psychol Rev 2000;20:5:56192. http://www.ncbi.n/m.nih.gov/pubmed/10860167, https://doi.org/10.1016/ S0272-7358(98)00100-7.

20. Kessler RC, Avenevoli S, Ries Merikangas K. Mood disorders in children and adolescents: an epidemiologic perspective. Biol Psychiatry 2001:49:12:100214. https://doi.org/10.1016/S0006-3223(01)01129-5.
21. Pickles A, Hill J. Developmental pathways. In: Cicchetti D, Hoboken CDJ, editors. Developmental psychopathology Vol 1: Theory and method (pp 211-243). NJ: Wiley; 2006.

22. Cicchetti D. Development and psychopathology. In: Cicchetti D, Cohen DJ, editors. Developmental psychopathology Vol 1: Theory and method. Hoboken: Wiley; 2006. p. 1-23.

23. O'Connor TG. The persisting effects of early experiences on psychological development. In: Cicchetti D, Cohen DJ, editors. Developmental psychopathology $\mathrm{Vol}$ 1: Theory and method. Hoboken: Wiley; 2006. p. 202-34.

24. Goodman SH, Brand SR. Depression and early adverse experiences. In: Handbook of depression. Edited by Gotlib $1 \mathrm{H}$, Hammen CL. New York: The Guilford Press; 2009. p. 249-274.

25. Leis JA, Heron J, Stuart EA, Mendelson T. Associations between maternal mental health and child emotional and behavioral problems: does prenatal mental health matter? J Abnorm Child Psych. 2014;42(1):161-71. https://doi. org/10.1007/s10802-013-9766-4.

26. Reuben JD, Shaw DS. Resilience in the offspring of depressed mothers: variation across risk, domains, and time. Clin Child Fam Psychol Rev. 2015; 18(4):300-27. https://doi.org/10.1007/s10567-015-0195-5.

27. Bukowski WM, Rubin KH, Parker JG: Social competence: childhood and adolescence. In: International Encyclopedia of the Social \& Behavioral Sciences. edn. Edited by JS Neil, Paul BB. Oxford: Pergamon; 2001: 14258-64.

28. Merrell KW. Assessment of social skills and peer relationships, behavioral, social, and emotional assessment of children and adolescents. Mahwah: Lawrence Erlbaum Associates, Publishers; 1999

29. Lewinsohn PM. A behavioral approach to depression. In: RJFMM K, editor. The psychology of depression: contemporary theory and research. Washington, DC: Winston-Wiley; 1974. p. 157-78.

30. Libet JM, Lewinsohn PM. Concept of social skill with special reference to the behavior of depressed persons. J Consult Clin Psychol. 1973;40(2):30412. https://doi.org/10.1037/h0034530.

31. Segrin C, Flora J. Poor social skills are a vulnerability factor in the development of psychosocial problems. Hum Commun Res. 2000;26(3):489514. https://doi.org/10.1111/j.1468-2958.2000.tb00766.x.

32. Vanger P. An Assessment of Social Skills Deficiencies in Depression. Compr Psychiat. 1987;28(6):508-12. https://doi.org/10.1016/0010440x(87)90016-2.

33. Hammen C, Shih J, Altman T, Brennan PA. Interpersonal impairment and the prediction of depressive symptoms in adolescent children of depressed and nondepressed mothers. J Am Acad Child Adolesc Psychiatry. 2003;42(5): 571-7. https://doi.org/10.1097/01.CHI.0000046829.95464.E5.

34. Pargas RC, Brennan PA, Hammen C, Le Brocque R. Resilience to maternal depression in young adulthood. Dev Psychol. 2010;46(4):805-14. https://doi. org/10.1037/a0019817.

35. Collishaw S, Hammerton G, Mahedy L, Sellers R, Owen MJ, Craddock N, Thapar AK, Harold GT, Rice F, Thapar A. Mental health resilience in the adolescent offspring of parents with depression: a prospective longitudinal study. Lancet Psychiatry. 2016;3(1):49-57. https://doi.org/10. 1016/S2215-0366(15)00358-2.

36. Gundersen KK. Social emotional competence - too much or too little. Int J Emot Educ. 2014;6(1):4-13. https://www.um.edu.mt/_ data/assets/pdf file/ 0016/215152/v6i1p1.pdf.

37. Kaukiainen A, Salmivalli C, Lagerspetz K, Tamminen M, Vauras M, Maki $H$, Poskiparta E. Learning difficulties, social intelligence, and self-concept: Connections to bully-victim problems. Scand J Psychol. 2002;43(3):26978. https://doi.org/10.1111/1467-9450.00295.

38. Solantaus-Simula T, Punamaki RL, Beardslee WR. Children's responses to low parental mood. I: balancing between active empathy, overinvolvement, indifference, and avoidance. J Am Acad Child Adolesc Psychiatry. 2002;41(3): 278-86. https://doi.org/10.1097/00004583-200203000-00007.

39. Tully EC, Donohue MR. Empathic responses to Mother's emotions predict internalizing problems in children of depressed mothers. Child Psychiatry Hum Dev. 2016; https://doi.org/10.1007/s10578-016-0656-1.

40. Greenberg MT, Domitrovich C, Bumbarger B. The prevention of mental disorders in school-aged children: current state of the field. Prev Treatment 2001:4:1. https://doi.org/10.1037/1522-373641.41a .

41. Durlak JA, Wells AM. Primary prevention mental health programs for children and adolescents: a meta-analytic review. Am J Community Psychol. 1997;25(2):115-52. https://doi.org/10.1023/A:1024654026646. 
42. Cyranowski JM, Frank E, Young E, Shear MK. Adolescent onset of the gender difference in lifetime rates of major depression: a theoretical model. Arch Gen Psychiatry. 2000;57(1):21-7. https://doi.org/10.1001/archpsyc.57.1.21.

43. Hankin BL, Abramson LY. Development of gender differences in depression: description and possible explanations. Ann Med. 1999;31(6):372-9. http:// www.ncbinlm.nih.gov/pubmed/10680851.

44. Zahn-Waxler C, Crick N, Shirtcliff EA R, Wood KE. The origins and development of psychopathology in females and males. In: Cicchetti D, Cohen DJ, editors. Developmental Psychopathology. 2nd ed. Hoboken: Wiley; 2006. p. 76-138.

45. Goodman SH, Gotlib IH. Risk for psychopathology in the children of depressed mothers: a developmental model for understanding mechanisms of transmission. Psychol Rev. 1999;106(3):458-90. https://doi.org/10.1037/ 0033-295X.106.3.458

46. Tronick E, Reck C. Infants of depressed mothers. Harv Rev Psychiatry. 2009; 17(2):147-56. https://doi.org/10.1080/10673220902899714.

47. Fergusson DM, Horwood LJ, Lynskey MT. Maternal depressive symptoms and depressive symptoms in adolescents. J Child Psychol Psychiatry. 1995; 36(7):1161-78. https://doi.org/10.1111/j.1469-7610.1995.tb01363.x.

48. Bureau JF, Easterbrooks MA, Lyons-Ruth K. Maternal depressive symptoms in infancy: Unique contribution to children's depressive symptoms in childhood and adolescence? Dev Psychopathol. 2009;21(2):519-37. https:// doi.org/10.1017/S0954579409000285.

49. Spence SH, Najman JM, Bor W, O'Callaghan MJ, Williams GM. Maternal anxiety and depression, poverty and marital relationship factors during early childhood as predictors of anxiety and depressive symptoms in adolescence. J Child Psychol Psychiat Allied Disciplines. 2002;43(4):457-69. https://doi.org/10.1111/1469-7610.00037.

50. Rose AJ, Rudolph KD. A review of sex differences in peer relationship processes: potential trade-offs for the emotional and behavioral development of girls and boys. Psychol Bull. 2006;132(1):98-131. https://doi. org/10.1037/0033-2909.132.1.98.

51. Eberhart NK, Shih JH, Hammen CL, Brennan PA. Understanding the sex difference in vulnerability to adolescent depression: an examination of child and parent characteristics. J Abnorm Child Psychol. 2006;34(4):495-508. https://doi.org/10.1007/s10802-006-9020-4.

52. Kaasboll J, Ranoyen I, Nilsen W, Lydersen S, Indredavik MS. Associations between parental chronic pain and self-esteem, social competence, and family cohesion in adolescent girls and boys - family linkage data from the HUNT study. BMC Public Health. 2015;15;ARTN 817. https://doi.org/10.1186/ s12889-015-2164-9.

53. Skrove M, Romundstad P, Indredavik MS. Resilience, lifestyle and symptoms of anxiety and depression in adolescence: the young-HUNT study. Soc Psych Psych Epid. 2013;48(3):407-16. https://doi.org/10.1007/s00127-012-0561-2.

54. von Soest T, Mossige S, Stefansen K, Hjemdal O. A validation study of the resilience scale for adolescents (READ). J Psychopathol Behav. 2010;32(2): 215-25. https://doi.org/10.1007/s10862-009-9149-x.

55. Hammen C, Brennan PA, Keenan-Miller D. Patterns of adolescent depression to age 20: the role of maternal depression and youth interpersonal dysfunction. J Abnorm Child Psychol. 2008;36(8):1189-98. https://doi.org/10. 1007/s10802-008-9241-9.

56. Mathiesen KS, Tambs K, Dalgard OS. The influence of social class, strain and social support on symptoms of anxiety and depression in mothers of toddlers. Soc Psych Psych Epid. 1999;34(2):61-72. https://doi.org/10.1007/ s001270050113.

57. Nilsen W, Kieldsen A, Karevold EB, Skipstein A, Helland M, Gustavson K Enstad F, Baardstu S, Røysamb E, von Soest T, et al. Cohort profile: the tracking opportunities and problems study (TOPP) - a study of Norwegian children and their parents followed from infancy to adulthood. Int J Epidemiol. 2017;46(5). https://doi.org/10.1093/ije/dyx057.

58. Gustavson K, von Soest T, Karevold E, Roysamb E: Attrition and generalizability in longitudinal studies: findings from a 15-year populationbased study and a Monte Carlo simulation study. BMC Public Health. 2012 12. https://doi.org/10.1186/1471-2458-12-918

59. Karevold E, Roysamb E, Ystrom E, Mathiesen KS. Predictors and pathways from infancy to symptoms of anxiety and depression in early adolescence. Dev Psychol. 2009:45(4):1051-60. https://doi.org/10.1037/a0016123.

60. Nilsen W, Gustavson K, Roysamb E, Kjeldsen A, Karevold E. Pathways from Maternal Distress and Child Problem Behavior to Adolescent Depressive Symptoms: A Prospective Examination from Early Childhood to Adolescence. J Dev Behav Pediatr. 2013; 34:5:303-13. https://doi.org/10. 1097/DBP.0b013e318293ab05.
61. Kjeldsen A, Nilsen W, Gustavson K, Skipstein A, Melkevik O, Karevold EB. Predicting Well-Being and Internalizing Symptoms in Late Adolescence From Trajectories of Externalizing Behavior Starting in Infancy. J Res Adolescence. 2016;26(4). https://doi.org/10.1111/jora.12252.

62. Hesbacher PT, Rickels K, Morris RJ, Newman H, Rosenfeld H. Psychiatric illness in family practice. J Clin Psychiatry. 1980;41(1):6-10. http://psycnet. apa.org/record/1981-05567-001.

63. Winokur A, Winokur DF, Rickels K, Cox DS. Symptoms of emotional distress in a family planning service: stability over a four-week period. Br J Psychiatry. 1984;144:395-9. http://dx.doi.org/10.1192/bjp.144.4.395.

64. Derogatis LR, Lipman RS, Rickels K, Uhlenhuth EH, Covi L. The Hopkins symptom checklist (HSCL): a self-report symptom inventory. Behav Sci. 1974; 19(1):1-15. https://doi.org/10.1002/bs.3830190102.

65. Tambs K, Moum T. How Well Can a Few Questionnaire Items Indicate Anxiety and Depression. Acta Psychiat Scand. 1993;87(5):364-7. https://doi. org/10.1111/j.1600-0447.1993.tb03388.x.

66. Messer SC, Angold A, Costello EJ, Loeber R, VanKammen W, StouthamerLoeber M. Development of a short questionnaire for use in epidemiological studies of depression in children and adolescents: Factor composition and structure across development. Int J Method Psych. 1995; 5: 4:251-62://WOS:A1995TQ48000003.

67. Angold A, Costello EJ, Messer SC, Pickles A, Winder F, Silver D: Development of a short questionnaire for use in epidemiological studies of depression in children and adolescents. Int J Method Psych. 1995; 5:4:237-49.

68. Sund AM, Larsson B, Wichstrom L: Depressive symptoms among young Norwegian adolescents as measured by The Mood and Feelings Questionnaire (MFQ). Eur Child Adoles Psy. 2001; 10:4:222-29. https://doi. org/10.1007/s007870170011.

69. Larsson B, Ingul J, Jozefiak T, Leikanger E, Sund AM. Prevalence, stability, 1year incidence and predictors of depressive symptoms among Norwegian adolescents in the general population as measured by the short mood and feelings questionnaire. Nord J Psychiatry. 2016;70(4):290-6. https://doi.org/ 10.3109/08039488.2015.1109137.

70. Gresham FM, Elliott SN. Social skills rating system manual. Circle Pines: American Guidance Service; 1998.

71. Diperna JC, Volpe RJ. Self-report on the social skills rating system: analysis of reliability and validity for an elementary sample. Psychol Schools. 2005;42(4): 345-54. https://doi.org/10.1002/pits.20095.

72. Ogden T. Kompetanse i kontekst. En studie av risiko og kompetanse hos 10 og 13 åringer [Norwegian]. Oslo: Child Welfare Development Centre; 1995.

73. Frostad P, Pijl SJ. Does being friendly help in making friends? The relation between the social position and social skills of pupils with special needs in mainstream education. Eur J Spec Needs Educ. 2007;22(1):15-30.

74. Gamst-Klaussen T, Rasmussen LMP, Svartdal F, Stromgren B. Comparability of the social skills improvement system to the social skills rating system: a Norwegian study. Scand J Educ Res. 2016;60(1):20-31. https://doi.org/10. 1080/00313831.2014.971864

75. Nilsen W, Karevold E, Roysamb E, Gustayson K, Mathiesen KS. Social skills and depressive symptoms across adolescence: social support as a mediator in girls versus boys. J Adolescence. 2013;36(1):11-20. https://doi.org/10. 1016/j.adolescence.2012.08.005.

76. Sandanger I, Moum T, Ingebrigtsen G, Dalgard OS, Sorensen T, Bruusgaard D. Concordance between symptom screening and diagnostic procedure: the Hopkins Symptom Checklist-25 and the Composite International Diagnostic Interview I. Soc Psych Psych Epid. 1998;33:7:345-54. https://doi. org/10.1007/s001270050064

77. Strand BH, Dalgard OS, Tambs K, Rognerud M. Measuring the mental health status of the Norwegian population: a comparison of the instruments SCL25, SCL-10, SCL-5 and MHI-5 (SF-36). Nord J Psychiatry. 2003;57(2):113-8. https://doi.org/10.1080/08039480310000932.

78. Hammen C. Adolescent depression: stressful interpersonal contexts and risk for recurrence. Curr Dir Psychol Sci. 2009;18(4):200-4. https://doi.org/10. 1111/j.1467-8721.2009.01636.x.

79. Beardslee WR, Schultz LH, Selman RL. Level of social-cognitive development, adaptive functioning, and Dsm-iii diagnoses in adolescent offspring of parents with affective-disorders - implications of the development of the capacity for mutuality. Dev Psychol. 1987;23(6):807-15. https://doi.org/10. 1037//0012-1649236.807.

80. Downey G, Walker E. Social cognition and adjustment in children at risk for psychopathology. Dev Psychol. 1989;25(5):835-45. https://doi.org/10.1037/ 0012-1649255.835. 
81. Sweeney S, MacBeth A. The effects of paternal depression on child and adolescent outcomes: a systematic review. J Affect Disord. 2016;205:44-59. https://doi.org/10.1016/j.jad.2016.05.073.

82. Lewis $G$, Neary M, Polek E, Flouri E, Lewis $G$. The association between paternal and adolescent depressive symptoms: evidence from two population-based cohorts. Lancet Psychiatry. 4:12:920-26. https://doi.org/ 10.1016/S2215-0366(17)30408-X.

83. Sellers R, Hammerton G, Harold GT, Mahedy L, Potter R, Langley K, Thapar A, Rice F, Thapar A, Collishaw S. Examining whether offspring psychopathology influences illness course in mothers with recurrent depression using a high-risk longitudinal sample. J Abnorm Psychol. 2016; 125(2):256-66. https://doi.org/10.1037/abn0000080.

84. Gresham FM, Elliott SN, Vance MJ, Cook CR. Comparability of the social skills rating system to the social skills improvement system: content and psychometric comparisons across elementary and secondary age levels. Sch Psychol Q. 2011;26(1):27-44. https://doi.org/10.1037/a0022662.

85. The Norwegian Directorate of Integration and Diversity (IMDi). A welfare state. 2017. Retrieved from http://www.nyinorge.no/en/Familiegjenforening/ New-in-Norway/About-Norway/History/A-welfare-state/.

Submit your next manuscript to BioMed Central and we will help you at every step:

- We accept pre-submission inquiries

- Our selector tool helps you to find the most relevant journal

- We provide round the clock customer support

- Convenient online submission

- Thorough peer review

- Inclusion in PubMed and all major indexing services

- Maximum visibility for your research

Submit your manuscript at www.biomedcentral.com/submit
Biomed Central 